\title{
Elección 2012: las reglas del dinero
}

\section{Ciro Murayama*}

\section{Sumario:}

I. Dinero y política: una relación inevitable

II. Los antecedentes en México

III. La reforma constitucional de 2007

IV. Las cifras de dinero para la elección de 2012

V. Los desafíos

* Profesor en la Facultad de Economía de la UNAM.

D. R. (c) 2012. Universidad Nacional Autónoma de México-Instituto de Investigaciones Jurídicas. 


\section{Dinero y política: una relación inevitable}

La competencia electoral requiere que los diferentes actores políticos dispongan de recursos financieros para soportar sus estructuras de militantes y para desplegar sus campañas ante la ciudadanía. Siendo así, siempre que se celebran elecciones hay recursos económicos involucrados.

La relación entre dinero y democracia es, por tanto, estructural e inevitable. Se presenta lo mismo en democracias consolidadas que en democracias recientes; en sistemas parlamentarios o en presidenciales; en democracias del norte y del sur. Pero no se trata de una relación tersa ni necesariamente productiva: la influencia del dinero o, dicho con más precisión, del poder económico en las contiendas electorales puede afectar al ejercicio de igualdad entre los ciudadanos que presupone una votación democrática. Mientras que todos los electores tienen el mismo poder de influencia a través de su sufragio ("un ciudadano, un voto"), los recursos económicos en las sociedades de mercado - antes llamadas capitalistas - se encuentran desigualmente distribuidos.

Así, si bien los recursos económicos son necesarios para que existan contiendas políticas genuinas, la influencia sin límites del dinero puede desnaturalizar una contienda democrática. En virtud de lo anterior los diferentes países se han dotado de normas para regular los flujos de dinero en la vida político-electoral. Éste es uno de los temas controvertidos pero indispensables de todo sistema electoral contemporáneo, como lo es también el referido a la importancia de los medios de comunicación masiva en los procesos políticos.

\section{Los antecedentes en México}

En México la regulación del dinero y del acceso a los medios se volvió central a partir de la reforma constitucional en materia electoral de 1996 - si bien tenía antecedentes que datan de la época de la llamada "reforma política" de fines de los años setenta del siglo XX- En la segunda mitad de la década de los noventa se definieron las bases de lo que sería el modelo de las condiciones de la competencia que 
produciría fenómenos como la pérdida del control del Congreso de la Unión por parte del partido del presidente así como la alternancia en el Ejecutivo federal.

Las definiciones clave del modelo fueron las siguientes: ${ }^{1}$ 1) predominancia del financiamiento público sobre el privado, y una regla equitativa de distribución de los recursos entre partidos; 2) límites a los montos de las aportaciones privadas y publicidad plena de las mismas; 3) prohibición de la donación de recursos a los partidos por parte de determinadas fuentes - las instituciones y los poderes públicos salvo lo expresamente marcado por la ley; las iglesias y sus ministros; donativos provenientes del extranjero; empresas mercantiles-; 4) topes de gasto en todas las campañas electorales; 5) acceso a los medios electrónicos de comunicación a través de tiempos de Estado y posibilidad de compra de tiempos y espacios de publicidad electoral sólo para los partidos políticos, y 6) una fiscalización permanente de los recursos de los partidos por parte del Instituto Federal Electoral (IFE). Estas disposiciones resultaron fundamentales para la consolidación del sistema de partidos.

La existencia de un sistema de financiamiento público predominante se basa en la búsqueda de cuatro grandes objetivos complementarios. El primero es asegurar la existencia de los partidos mismos, que en la Constitución son considerados desde 1977 como "entidades de interés público". En segundo lugar, se trata de garantizar su autonomía frente a grupos de poder económico y, peor aún, delincuencial, pues si dependieran del dinero privado correrían el riesgo de verse "capturados" por los intereses de los particulares que los sostuvieran; en tercer lugar, el financiamiento público intenta crear un terreno de juego parejo para los contendientes, en el que las diferencias económicas no resulten el elemento definitorio y, en cuarto término, al haber recursos públicos bien identificados se impulsa la transparencia en los flujos monetarios de que disponen los partidos políticos.

En la equidad de la contienda se estableció una clara regla de distribución de los recursos entre partidos: el 30\% de forma igualitaria y el $70 \%$ restante en función del porcentaje alcanzado por cada fuerza en la elección inmediata anterior a la Cámara de Diputados. El avance en este terreno fue significativo. Por ejemplo, si en la campaña electo-

1 Becerra, Ricardo et al., La mecánica del cambio político en México, México, Cal y Arena, 2000. 
ral de 1994, la última celebrada antes de la reforma constitucional de 1996, el Partido Revolucionario Institucional (PRI) gastó ocho de cada diez pesos erogados por el conjunto de fuerzas políticas, para la campaña de la siguiente elección presidencial, la del año 2000, los tres principales partidos - el PRI, Acción Nacional (PAN) y el de la Revolución Democrática (PRD) - dispusieron de una suma similar de recursos. Lo anterior es una elocuente muestra de cómo las diferencias en las capacidades económicas de los contendientes políticos se habían logrado equilibrar gracias a la reforma.

El financiamiento privado se hizo más transparente, de tal manera que en los primeros años del siglo cobró carta de naturalidad el hecho de que en el portal de Internet del IFE se fueran haciendo públicas las listas de donadores a los partidos políticos una vez que se finalizaba la tarea de fiscalización de las cuentas de las campañas electorales. Pero hay que señalar que el financiamiento privado también perdió importancia. En cuanto los partidos tuvieron asegurado un suministro estable y conocido de recursos públicos no tuvieron que depender del financiamiento privado o del autofinanciamiento - por ejemplo a través de rifas y sorteos, que eran prácticas extendidas y conocidas, de forma destacada en el Partido Acción Nacional, durante décadas-.

A lo largo de la predominancia del sistema de partido hegemónico en México no había una distinción clara entre el gobierno y el Estado mexicanos, y tampoco entre el partido en el gobierno y el gobierno mismo. Por lo anterior, no era inusual que los recursos públicos se canalizaran a las actividades del partido en el gobierno desde cualquier nivel de las administraciones públicas, lo mismo en el plano federal que en el local y el municipal. Para acabar con tales prácticas y para permitir unas condiciones de la competencia adecuadas, además de transparentar y etiquetar desde las autoridades electorales y sólo desde ellas cuáles eran los montos de recursos públicos que podían fluir a los partidos políticos, se introdujo al código penal como delito el usar gasto público con fines partidistas. Así, la ley estableció expresamente que ningún funcionario público puede utilizar los recursos del erario para favorecer a partido o candidato alguno.

Si por el lado de los ingresos se buscó crear condiciones equitativas, el marco legal no podía dejar de atender el tema de las erogaciones, de los gastos. Ése fue el propósito de fijar topes de gasto para cada campaña electoral, de tal suerte que ningún partido o candidato pudiera tomar una ventaja ilegítima por el uso desmesurado de recursos en 
una contienda, incluso si esos recursos fueran de procedencia legítima. Esta disposición se ha visto vulnerada en diferentes ocasiones, lo que ha merecido sanción por parte de las autoridades electorales. El caso más emblemático lo representa la multa a los partidos Acción Nacional y Verde Ecologista de México por haber superado el tope de gasto de campaña en la elección presidencial de $2000 .^{2}$

En el acceso a los medios de comunicación, la reforma electoral de 1996, así como el propio desarrollo de las telecomunicaciones y la creciente influencia de los medios en el imaginario colectivo, propiciaron que éste se volviera el núcleo de las campañas electorales. Con cargo a los tiempos oficiales del Estado, los partidos aparecieron con mayor frecuencia en la radio y la televisión, pero como también se permitió que se diera la compra directa por parte de los partidos políticos -y sólo por ellos - de tiempos y espacios para la publicidad electoral, se propició una espiral creciente de gasto en los medios electrónicos y, consecuentemente, de encarecimiento de los costos de las campañas electorales. ${ }^{3}$ Como se verá más adelante, el acceso a la radio y la televisión se volvería uno de los asuntos críticos de la vida político electoral del país.

En materia de fiscalización electoral, el modelo de regulación contribuyó a transparentar e institucionalizar el manejo de los recursos de los partidos políticos, que antes se hacía de manera tan discrecional como opaca. La fiscalización que se realiza en México a los partidos políticos es exhaustiva ${ }^{4}$ y una de las más rigurosas si se realizan ejercicios comparativos a nivel internacional. Tan es así que en México se aplicaron dos sanciones sin parangón por financiamiento irregular a los partidos políticos: a) al PRI por el caso conocido como "Pemexgate" con una multa de 100 millones de dólares, y b) al PAN y PVEM por el caso "Amigos de Fox" de financiamiento ilegal a la campaña de quien era presidente en turno al momento de la sanción.

A partir de que comenzó a operar este modelo de regulación de las condiciones de la competencia, en México se normalizaron fenómenos político-democráticos hasta entonces desconocidos, como el hecho de que ninguna fuerza política logre obtener tal ventaja sobre

2 Córdova, Lorenzo y Murayama, Ciro, Elecciones, dinero y corrupción. Pemexgate y Amigos de Fox, México, Cal y Arena, 2006.

3 Trejo, R., Poderes salvajes, mediocracia sin contrapesos, México, Cal y Arena, 2005.

4 Zavala, M. A., "La fiscalización de los recursos", en Córdova, Lorenzo y Salazar, Pedro, Estudios sobre la reforma electoral 2007, México, TEPJF, 2008. 
el resto como para hacerse de la mayoría en la Cámara de Diputados -que durante cinco legislaturas no ha tenido mayorías absolutas de un solo partido- o del Senado - que se ha renovado en dos ocasiones, 2000 y 2006, sin que se configuren mayorías unipartidistas-, así como la alternancia en 2000 de la Presidencia de la República o una elección sumamente competida, sin ganador predeterminado, en la elección presidencial de 2006 - cuando la diferencia entre Felipe Calderón y Andrés Manuel López Obrador fue de 0.56\%-.

A pesar de los avances democráticos que el modelo de competencia partidista facilitó, lo cierto es que en su aplicación se evidenciaron diversos fallos que era necesario corregir, sobre todo por el controvertido desenlace de la elección de 2006 que puso en tela de duda la legitimidad de los procesos electorales en el país.

\section{La reforma constitucional de 2007}

En la elección presidencial de 2006 diversos actores se resistieron a cumplir la ley en materia de las condiciones de la competencia. Si bien desde el Cofipe aprobado en 1996 existía la determinación de que sólo los partidos políticos pudiesen adquirir tiempo en radio y televisión para tratar de influir en las preferencias de los ciudadanos y, por tanto, esa compra le estaba vetada al resto de los actores, ${ }^{5}$ en la elección de 2006 las campañas se vieron alteradas por la intromisión de anuncios comprados por particulares con fines electorales. Se trató de los spots contratados, por ejemplo, por el llamado "Dr. Simi” para hacerse de la candidatura presidencial del Partido Alternativa Socialdemócrata pero, sobre todo, de anuncios pagados por el Consejo Coordinador Empresarial contra la candidatura de López Obrador.

En esa ocasión, el IFE fue omiso en aplicar la ley. El consejero presidente del IFE entre 2003 y 2007, llegó a sostener que el IFE no tenía facultades legales para evitar tales conductas ("hubo exigencias al IFE

5 El artículo 48 del Cofipe, en su párrafo I asentaba: "Es derecho exclusivo de los partidos políticos contratar tiempos en radio y televisión para difundir mensajes orientados a la obtención del voto durante las campañas electorales", mientras que el párrafo 13 del mismo artículo complementaba con la siguiente disposición: "En ningún caso, se permitirá la contratación de propaganda en radio y televisión en favor o en contra de algún partido político o candidato por parte de terceros". 
para que contuviera la conducta de ciertos actores (por ejemplo, el presidente o los grupos empresariales)... Al no existir facultades claras o sanciones expresas en la ley para prevenir, prohibir o detener tales acontecimientos... se generó inconformidad en algunos actores políticos" $)$. No obstante esa peculiar lectura, el Tribunal Electoral del Poder Judicial de la Federación (TEPJF) consideró, al calificar la elección de 2006, ilegal la intromisión empresarial que el IFE dejó pasar por alto.

Tras esa experiencia y para subrayar la importancia que tiene el evitar que grupos particulares puedan alterar las condiciones de la competencia electoral, en la reforma de 2007 se elevó a rango constitucional la prohibición de que terceros realicen compras en radio y televisión para emitir mensajes que pretendan favorecer o afectar a cualquier partido o candidato.

Asimismo, los partidos habían alcanzado unos niveles de gasto excesivos en radio y televisión, lo que implicaba que buena parte de los recursos públicos entregados a los partidos terminaran siendo trasladados a las empresas de la telecomunicación en un país de alta concentración oligopólica en tal mercado. Además, los precios que los concesionarios de la radio y la televisión establecían para los diferentes partidos no eran semejantes, de tal manera que el criterio de los particulares afectaba la equidad en la contienda. ${ }^{7}$

Lo anterior dio lugar a que en la reforma de 2007 la mayor novedad frente al modelo previo fuese la prohibición expresa para la compra de publicidad político electoral en México, ya fuese por particulares o por partidos políticos. Estos últimos, tendrían garantizado el acceso a los medios de comunicación electrónica exclusivamente a través de los tiempos de Estado. ${ }^{8}$

Esta disposición en los hechos permitió que los partidos políticos y sus candidatos no tuvieran la necesidad de conseguir ingentes cantidades de dinero para acceder a las pantallas de la televisión y a las ondas de la radio, es decir, para "existir" de cara a un electorado que en buena medida se informa a través de los medios electrónicos. La pro-

6 Ugalde, Luis Carlos, “Los dilemas del arbitraje electoral”, Nexos, núm. 347, 2006, pp. 46 y 47.

7 Murayama, Ciro, "Financiamiento a los partidos: el nuevo modelo mexicano", en Córdova, Lorenzo y Salazar, Pedro, op. cit.

8 Astudillo, César, "El nuevo sistema de comunicación política en la Reforma Electoral de 2007”, en Córdova, Lorenzo y Salazar, Pedro, op. cit. 
hibición de compra-venta de espacios de radio y televisión dio lugar, así, a una reducción importante de los recursos públicos destinados a las campañas políticas.

En este sentido, si en las campañas celebradas entre 1997 y 2006 a cada partido se le entregaba un monto de recursos del $100 \%$ de su financiamiento ordinario, a partir de la reforma de 2007 la cantidad es del 50\% adicional en una elección presidencial y del 30\% si sólo se renueva la Cámara de Diputados.

De la reforma electoral de 2007 también se desprende un acotamiento a las donaciones de los particulares a los partidos políticos y de los topes de gasto de campaña, así como el establecimiento de topes de gasto por primera vez para las precampañas.

A continuación se presentan las cifras de los recursos que los partidos estarán recibiendo y podrán gastar durante las campañas de 2012.

\section{Las cifras de dinero para la elección de 2012}

El financiamiento ordinario de los partidos políticos se calcula a partir de la reforma electoral de 2007 de la siguiente forma: se toma en cuenta el tamaño del padrón y se multiplica por el $65 \%$ del salario mínimo diario vigente en la capital del país. El corte del padrón al 31 de julio de 2011 fue de 82859268 ciudadanos; el salario mínimo aprobado en diciembre de 2009 fue de 59.82 pesos, y si se considera un aumento del 3\% en el salario mínimo al finalizar 2011, entonces la multiplicación del padrón por el 65\% del salario mínimo arroja la cifra de 3318271425 pesos de financiamiento ordinario para los partidos políticos durante 2012 .

Para gastos de campaña, debe considerarse un 50\% adicional de esa cifra, lo que asciende a 1659 millones de pesos. Como el criterio de reparto corresponde a un $30 \%$ igualitario y un $70 \%$ proporcional al resultado de la última elección federal a diputados, entonces el PRI dispondrá del 32\% del total, el PAN del 25\% y el PRD del 13\% (véase cuadro 1).

Una eventual política de alianzas del PRI con el PVEM y el Panal daría lugar a que esa posible coalición acumulara cerca de la mitad del financiamiento público para gastos de campaña (48\%) en el proceso electoral de 2012. Por su parte, una probable coalición electoral del 
PRD con el Movimiento Ciudadano (antes Convergencia) y el Partido del Trabajo supondría reunir el 26\% de los recursos públicos para gastos de campaña, cifra similar a la que dispondrá por sí solo el PAN (25\%).

Cuadro 1.

Estimación de montos de financiamiento federal para los partidos políticos en 2012 (pesos corrientes)

\begin{tabular}{|c|c|c|c|c|}
\hline & Ordinario & Campaña & Total & $\begin{array}{c}\text { Porcentaje } \\
\text { por partido }\end{array}$ \\
\hline PAN & 838788116 & 419394058 & 1258182175 & $25 \%$ \\
\hline PRI & 1060904824 & 530452412 & 1591357237 & $32 \%$ \\
\hline PRD & 445761741 & 222880870 & 668642611 & $13 \%$ \\
\hline PT & 233199174 & 116599587 & 349798761 & $7 \%$ \\
\hline PVEM & 309042351 & 154521175 & 463563526 & $9 \%$ \\
\hline MC & 203504788 & 101752394 & 305257183 & $6 \%$ \\
\hline PANAL & 227270430 & 113635215 & 340905645 & $7 \%$ \\
\hline Total & 3318471425 & 1659235713 & 4977707138 & $100 \%$ \\
\hline
\end{tabular}

Fuente: elaboración propia.

Ahora bien, en lo que se refiere a los topes de gasto se tiene lo siguiente.

Para la elección presidencial, de acuerdo al artículo 229 del Cofipe: "El tope máximo de gastos de campaña será equivalente al veinte por ciento del financiamiento público de campaña establecido para todos los partidos en el año de la elección presidencial". Esto da un monto de 332 millones de pesos ( 331847000 pesos, que surgen de estimar el $20 \%$ de los 1659 millones de pesos que se estarán entregando desde el IFE para gasto de campaña a partidos y candidatos federales). Esta cifra, 332 millones, deberá ser escrupulosamente respetada por los actores políticos y verificada por las autoridades electorales.

En las campañas a diputados de mayoría relativa, el tope de gasto se estima dividiendo entre 300 - que son los distritos electorales federales que componen al territorio nacional- el tope de la elección presidencial. El resultado es que cada candidato a diputado podrá gastar un poco más de un millón de pesos (1 106157 pesos) en las campañas de 2012. 
Los candidatos al Senado de la República, por su parte, deberán sujetarse a lo siguiente: "El tope máximo para gastos de campaña será la cantidad que resulte de multiplicar la suma del tope de gasto de campaña para la elección de diputados por el número de distritos que comprenda la entidad de que se trate. En ningún caso el número de distritos que se considerará será mayor de veinte" (artículo 229 del Cofipe). Siendo así, una entidad como Baja California Sur o Colima con dos distritos, el tope de gasto será de 2.2 millones de pesos; en cambio, en el Distrito Federal, el Estado de México o Veracruz, el tope será de 22.12 millones de pesos.

Cuadro 2.

Estimación de tope de gasto en campañas para senadores 2012 (pesos)

\begin{tabular}{|c|c|c|c|c|c|}
\hline Entidad & Distritos & $\begin{array}{c}\text { Tope gasto } \\
\text { senadores }\end{array}$ & Entidad & Distritos & $\begin{array}{c}\text { Tope gasto } \\
\text { senadores }\end{array}$ \\
\hline Aguascalientes & 3 & 3318471 & Morelos & 5 & 5530786 \\
\hline Baja California & 8 & 8,849257 & Nayarit & 3 & 3318471 \\
\hline $\begin{array}{c}\text { Baja California } \\
\text { Sur }\end{array}$ & 2 & 2212314 & Nuevo León & 12 & 13273886 \\
\hline Campeche & 2 & 2212314 & Oaxaca & 11 & 12167729 \\
\hline Coahuila & 7 & 7743100 & Puebla & 16 & 17698514 \\
\hline Colima & 2 & 2212314 & Querétaro & 4 & 4424629 \\
\hline Chiapas & 12 & 13273886 & Quintana Roo & 3 & 3318471 \\
\hline Chihuahua & 9 & 9955414 & San Luis Potosí & 7 & 7743100 \\
\hline Distrito Federal & 27 & 22123143 & Sinaloa & 8 & 8849257 \\
\hline Durango & 4 & 4424629 & Sonora & 7 & 7743100 \\
\hline Guanajuato & 14 & 15486200 & Tabasco & 6 & 6636943 \\
\hline Guerrero & 9 & 9955414 & Tamaulipas & 8 & 8849257 \\
\hline Hidalgo & 7 & 7743100 & Tlaxcala & 3 & 3318471 \\
\hline Jalisco & 19 & 21016986 & Veracruz & 21 & 22123143 \\
\hline $\begin{array}{c}\text { Estado de } \\
\text { México }\end{array}$ & 40 & 22123143 & Yucatán & 5 & 5530786 \\
\hline Michoacán & 12 & 13273886 & Zacatecas & 4 & 4424629 \\
\hline & & TOTAL & 300 & 300874743 \\
\hline Funte: & & & & 5 & 5 \\
\hline
\end{tabular}

Fuente: elaboración propia. 
Si se suman los datos anteriores, se tiene que, como máximo, lo que un partido político o coalición podrían gastar son 964.6 millones de pesos (ver cuadro 3).

Cuadro 3.

Estimación de límites de gasto por partido o coalición en 2012

\begin{tabular}{|l|l|}
\hline Tope de gasto en campaña presidencial & 331847143 \\
\hline Tope de gasto en 300 campañas de diputados & 331847143 \\
\hline Tope de gasto en 32 campañas a senadores & 300874743 \\
\hline Total de gasto máximo & 964569028 \\
\hline
\end{tabular}

Fuente: Elaboración propia

Una de las novedades de la reforma electoral de 2007 es que norma lo que acontece durante los periodos internos de los partidos políticos para seleccionar a sus candidatos a las elecciones constitucionales, esto es, se regulan las llamadas precampañas.

El artículo 214 del Cofipe define que "el tope será equivalente al veinte por ciento del establecido para las campañas inmediatas anteriores, según la elección de que se trate”. En 2008 se estimó, tras la reforma electoral, que el tope de gasto de la campaña presidencial que habría correspondido con la nueva fórmula sería de 234 millones de pesos. Siendo así, los precandidatos a la presidencia podrán gastar hasta 46795000 pesos (el 20\% de los 233.9 millones de topes que se determinó que habría sido el tope para la elección presidencial de 2006 de haberse aplicado la fórmula vigente); los precandidatos a diputados podrán erogar hasta 162000 pesos (el 20\% de los 812 mil pesos que fueron el tope de gasto por campaña en 2009) y, los precandidatos a senadores tendrán topes que irán desde los 325000 pesos —en entidades con sólo dos distritos - a los 3250000 pesos —en entidades con veinte o más distritos-.

En lo que toca al financiamiento privado, desde la Constitución se ponen límites a los recursos al determinar que la "ley establecerá el monto máximo que tendrán las aportaciones de sus simpatizantes [de los partidos], cuya suma total no podrá exceder anualmente, para cada partido, al diez por ciento del tope de gastos establecido para la última campaña presidencial" (artículo 41, base II, inciso c). En atención a que el tope de gasto de la campaña presidencial que se estimó 
tras la reforma electoral fue de 234 millones de pesos, lo que los partidos podrán recabar por sus simpatizantes tendrá un límite de 23.4 millones de pesos.

Además, la ley marca como límite al gasto de cada persona física o moral el $0.5 \%$, anual, del tope de gasto de la campaña presidencial anterior. Ese monto, para 2012, será de un millón 169 mil pesos. La idea de esta restricción es incentivar a los partidos que busquen diversificar a las personas privadas que les hacen contribuciones y no dependan de unos cuantos donantes con donaciones voluminosas.

\section{Los desafíos}

Como se puede ver, en México se han actualizado las reglas para el ingreso y el gasto de recursos económicos de los partidos políticos de cara al proceso electoral que culminará con la elección del presidente de la República y la renovación del Congreso de la Unión en 2012. Las leyes mexicanas en la materia son precisas y no dejan lugar a equívocos.

El desafío en esta materia es pasar de las buenas normas a las buenas prácticas. El compromiso de los partidos y candidatos con la legalidad será definitorio. Pero también el contexto de exigencia que se les genere desde la academia, los medios de comunicación y la ciudadanía. Por supuesto, una responsabilidad central recae en las autoridades electorales encargadas de verificar el apego a la ley por parte de los actores políticos.

Si algún tema que competa directamente al entramado institucional y legal de las elecciones es delicado en el México actual, es precisamente el del dinero en la contienda política. De que las normas recién explicadas tengan validez plena puede depender la legalidad y la calidad de la elección federal de 2012 y con ella, la legitimidad de las instituciones públicas en su conjunto. 